\title{
Pharmaceutical care in smoking cessation
}

This article was published in the following Dove Press journal:

Patient Preference and Adherence

29 January 2015

Number of times this article has been viewed

\author{
Alicia Marín Armero' \\ Miguel A Calleja Hernandez ${ }^{2}$ \\ Sabina Perez-Vicente ${ }^{3}$ \\ Fernando Martinez-Martinez ${ }^{4}$ \\ 'Community Pharmacy, Murcia, \\ Spain; ${ }^{2}$ Hospital Pharmacy, University \\ Hospital Virgen de las Nieves, \\ Granada, Spain; ${ }^{3}$ Result Evaluation \\ Unit, Institute of Biomedicine, \\ Sevilla, Spain; ${ }^{4}$ Research Unit in \\ Pharmaceutical Care, University \\ of Granada, Granada, Spain
}

Abstract: As a determining factor in various diseases and the leading known cause of preventable mortality and morbidity, tobacco use is the number one public health problem in developed countries. Facing this health problem requires authorities and health professionals to promote, via specific programs, health campaigns that improve patients' access to smoking cessation services. Pharmaceutical care has a number of specific characteristics that enable the pharmacist, as a health professional, to play an active role in dealing with smoking and deliver positive smoking cessation interventions. The objectives of the study were to assess the efficacy of a smoking cessation campaign carried out at a pharmaceutical care center and to evaluate the effects of pharmaceutical care on patients who decide to try to stop smoking. The methodology was an open, analytical, pre-post intervention, quasi-experimental clinical study performed with one patient cohort. The results of the study were that the promotional campaign for the smoking cessation program increased the number of patients from one to 22, and after 12 months into the study, $43.48 \%$ of the total number of patients achieved total smoking cessation. We can conclude that advertising of a smoking cessation program in a pharmacy increases the number of patients who use the pharmacy's smoking cessation services, and pharmaceutical care is an effective means of achieving smoking cessation.

Keywords: community pharmacy, health campaign, tobacco cessation, nicotine replacement therapy

\section{Introduction}

As a determining factor in various diseases and the leading known cause of preventable mortality and morbidity, tobacco use is the number one public health problem in developed countries. In Spain, it is estimated that 55,000 people die every year from diseases directly linked to tobacco use. ${ }^{1}$ We are facing a significant public health problem that requires authorities and health professionals to promote, via specific programs, health campaigns that improve patients' access to smoking cessation services. ${ }^{2,3}$

Based on the available evidence, it is recommended that health professionals' involvement in smoking cessation interventions be based on criteria such as access to smokers, appropriate professional training, and each professional's interest and experience, rather than on the field in which they work. ${ }^{4}$ Community pharmacies can deliver regular interventions to a large number of healthy and ill people. Pharmacists, therefore, have an excellent opportunity to help promote good health and take part in disease prevention activities as part of their service to patients. Pharmacists' role as a provider of nicotine replacement therapy (NRT), available without prescription in Spain, means that they are ideally placed to support patients who want help to stop smoking, and they can ensure that patients have access to these kinds of programs. Their role should go further than the provision of advice on the correct use of pharmacological products to include providing appropriate advice and guidelines aimed at helping patients achieve abstinence and, when necessary, referring patients to the relevant health care providers. ${ }^{5}$
Correspondence: Alicia Marín Armero Community Pharmacy, San Martin de

Porres, I3, 3000I Murcia, Spain

Tel +3496824| 930

Email alicia@procamur.com 
Pharmaceutical care has a number of specific characteristics ${ }^{6}$ that enable the pharmacist, as a health professional, to play an active role in dealing with smoking and to deliver positive smoking cessation interventions. The studies performed to date indicate that interventions by suitably trained community pharmacy personnel can have a positive effect on smoking cessation rates. ${ }^{5}$

The objectives of this study were: 1) to assess the efficacy of a smoking cessation campaign carried out at a pharmaceutical care center; and 2) to evaluate the effects of pharmaceutical care on patients who decide to try to stop smoking.

\section{Materials and methods}

This was an open, analytical, pre-post intervention, quasi-experimental clinical study performed with one patient cohort. It was carried out in a pharmacy in the city of Murcia, Spain. The study population consisted of smokers who were patients of the pharmacy where the study on smoking cessation took place, and all smokers were contacted via the campaign promoting the pharmacy's smoking cessation service. All patients who came to the pharmacy over a period of 4 months (April-July, 2011) to ask for help to stop smoking were included.

To assess the primary objective, the pharmacy's smoking cessation service was offered to all patients who came to the pharmacy to ask for help to stop smoking during the study period. During the last 2 months of this period, a promotional campaign for a smoking cessation program was carried out. This campaign involved passing out leaflets to all the patients who visited the pharmacy (Figure 1) and displaying posters inside and outside the pharmacy (Figure 2). The promotional campaign was launched to coincide with "World No Tobacco

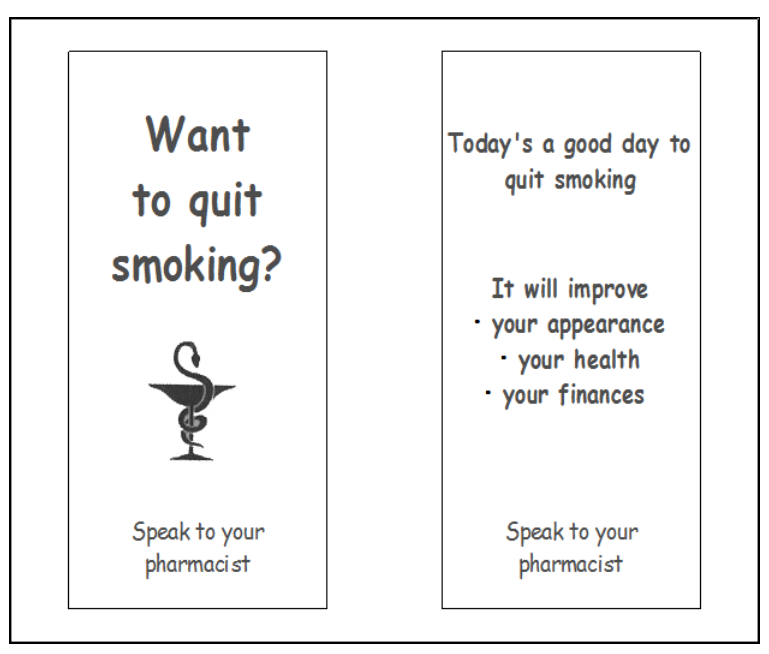

Figure I Leaflet given to pharmacy patients during the last 2 months of the study.

\section{Today's a good day to quit smoking}

\author{
3 \\ Come in \\ and speak to your pharmacist
}

Figure 2 Promotional poster for the smoking cessation campaign placed outside the pharmacy.

Day" (May 31, 2011), and the contents of the leaflets and posters were taken from awareness campaigns created by Spain's Ministry of Health and Social Services.

The dependent variable was the number of patients who enrolled in the program before and after the campaign. The Dader method ${ }^{7}{ }^{7}$ was used to assess the second objective, and seven patient follow-up visits were planned: the first between the first and third day after the patient stopped smoking; the second between days 7 and 15; and then subsequent visits at months 1,2, 3, 6, and 12 .

The inclusion criteria were as follows: all patients who smoked and were over 18 years old; ${ }^{9}$ who asked for help to stop smoking; and who agreed to register for the smoking cessation program.

The exclusion criterion included patients who smoked, but who did not want to take part in the study.

The independent variables included:

- Patient data

$\circ$ Age

- Sex

- Initial condition

- Number of cigarettes per day: discrete, categorical, numerical variable referring to the number of cigarettes consumed per day. Patients were categorized as smokers of ten or fewer cigarettes, 11-20 cigarettes, 21-30 cigarettes, and 31 or more cigarettes per day.

- CO-oximetry value: ${ }^{10}$ discrete, categorical, numerical variable measured in parts per million (ppm) indicating the quantity of carbon monoxide (CO) in the air exhaled by a subject. A Smoke Check Monitor ${ }^{\circledR}$ COoximeter was used to measure this parameter. Patients who were found to have 20 or more ppm of $\mathrm{CO}$ in exhaled air were classified as heavy smokers; patients with 11-20 ppm CO were classified as moderate smokers; patients with 7-10 ppm CO were classified 
as occasional smokers; and those with values of $6 \mathrm{ppm}$ $\mathrm{CO}$ or less were classified as nonsmokers. , $^{911,12}$

○ Nicotine dependence (Fagerstrom test): ${ }^{13}$ discrete, categorical, numerical variable to measure smokers' levels of physical dependence on nicotine. This is a six-question test with multiple choice answers (Table S1). A certain number of points are attributed to each question depending on the answer given by the smoker. The points for all of the questions are then added together to give a total of between 0 and 10 points. If the patient has a score of between 0 and 3 points, his level of dependence is judged to be low; a score of between 4 and 6 indicates moderate dependence; and a score of 7 or more indicates a high level of dependence.

- Smoking history

- Starting age: continuous, numerical variable indicating how old the patient was in years when he started smoking.

- Previous attempts: discrete, numerical variable indicating how many times the patient tried to stop smoking in the past.

o Treatment: nominal, qualitative variable indicating the therapy used by the patient during his previous attempts to stop smoking. The options were: the patient has not received any treatment; the patient has used NRT; the patient has used non-nicotine-based pharmaceutical treatments; the patient has used selfhelp resources; or the patient has used other treatments (such as acupuncture, homeopathy, and herbal medicines).

- Perception of difficulties: nominal, qualitative variable indicating the situations in which the patient found it difficult not to smoke. Smokers could choose from the following situations: social functions; work or study environment; leisure time and bars; smoking while alone; having a cigarette with coffee; or other.

The dependent variables included:

- Acceptance of pharmaceutical care: nominal, dichotomous, qualitative variable expressing the results as a percentage of patients who accepted help to stop smoking.

- Smoking cessation: qualitative, ordinal variable indicating abstinence as reported by the patient. Cessation could be positive or negative. If positive, it was categorized as either total or partial (the latter indicating a reduction in the number of cigarettes consumed). Partial cessation was recorded if the patient moved into a lower category. Four follow-up visits were planned to assess smoking cessation (at 1, 3, 6, and 12 months). The value of this variable was confirmed by measuring $\mathrm{CO}$ in exhaled air during each follow-up visit.

Patients were referred to a doctor in the following situations: ${ }^{9,14}$ if they were pregnant or breastfeeding; if they had been suffering from ischemic heart disease for less than 8 weeks; if they suffered from uncontrolled arrhythmias or uncontrolled high blood pressure; if they suffered from an uncontrolled chronic disease (neuropathic disorder, liver disease, heart disease, and so on); or if they had any psychiatric disorders.

All referred patients received both medical and pharmaceutical care. The pharmaceutical care comprised two components: psychological support and pharmacological treatment. Psychological support was offered at all visits and consisted of providing advice to patients to help them get ready to give up smoking, stay motivated, and avoid relapse. This involved the use of cognitive-behavioral techniques to develop the necessary skills and coping strategies, problem-solving techniques, and appropriate social support both during and after therapy sessions. ${ }^{15,16}$ This process was aimed at obtaining the results required for the smoking cessation variable.

The pharmacological treatment for those patients who needed it was NRT. ${ }^{17,18}$ In Spain, only chewing gum, patches, and tablets are currently available. If the Fagerstrom test score was $\leq 6$, the pharmacist recommended chewing gum or tablets as required for the patient to use before he experienced the need or intense desire to smoke. The patient was advised to limit the number of doses taken because nicotine is addictive in all forms of administration. The maximum daily dose was 20 pieces of $2 \mathrm{mg}$ gum or 15 pieces of $4 \mathrm{mg}$ gum, or $201 \mathrm{mg}$ tablets or $152 \mathrm{mg}$ tablets. The minimum recommended dose was one piece of gum or one tablet every 2-3 hours, with a usual dose being 8-12 pieces of gum or tablets. In order to provide personalized treatment, the pharmacist measured the quantity of nicotine generally consumed by each patient. If the patient smoked more than 20 cigarettes per day, $4 \mathrm{mg}$ gum or $2 \mathrm{mg}$ tablets were recommended. If the patient smoked less than 20 cigarettes per day, $2 \mathrm{mg}$ gum or $1 \mathrm{mg}$ tablets were recommended.

If the Fagerstrom test score was $>6$, the pharmacist recommended the use of nicotine patches, except in cases of insomnia. ${ }^{9}$ The pharmacist based the recommended patch type on the length of time between waking up and smoking the first cigarette. If this period was greater than $30 \mathrm{~min}-$ utes, the 16-hour patch was recommended. If this period was 


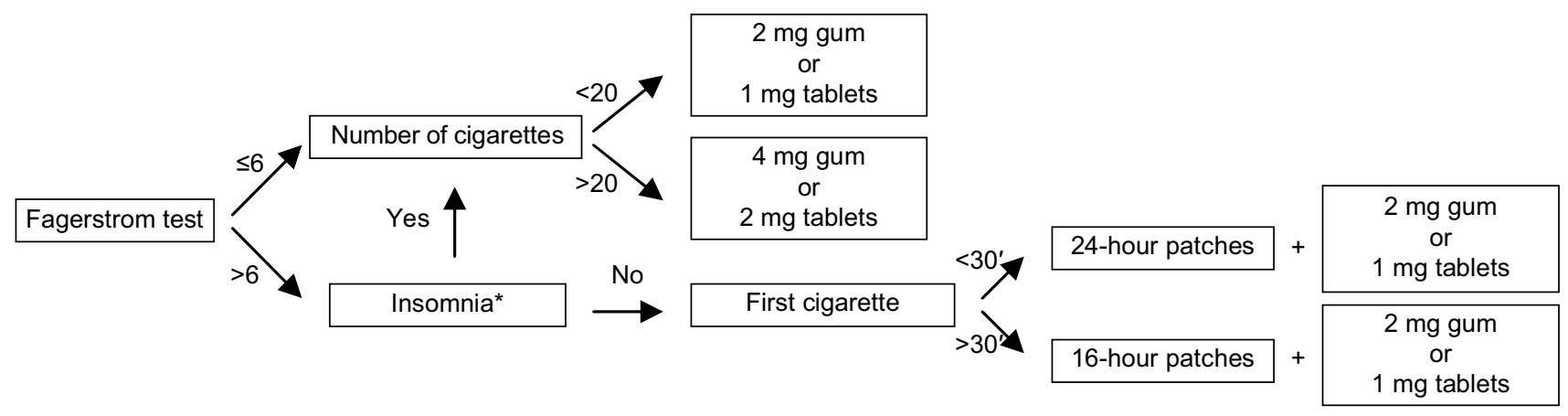

Figure 3 Treatment indication flow diagram

Note: *Nicotine patches are contraindicated in patients suffering from insomnia.

less than 30 minutes, the 24-hour patch was recommended. The use of patches was combined with low-dose gum or tablets to control cravings (Figure 3). The patients gave their consent to the choice of treatment.

\section{Results}

Overall, 25 patients were invited to participate in the study on smoking cessation, of which 23 (92\%) accepted the pharmacy's service and two (8\%) declined. During the first 2 months in which the pharmacy's service was offered to patients who asked for help to stop smoking, only one patient asked for help, and that one patient was enrolled in the study. During the following 2 months in which the promotional campaign for the smoking cessation program was running, 24 patients asked for help, of which 22 patients were enrolled in the study and two declined the offer of the pharmacy's service. This represents a 24-fold increase in the number of smokers who asked for help to stop smoking and a 22-fold increase in the number of patients who were enrolled in the study.

In the final study population, $69.57 \%$ of participants were female and $30.43 \%$ were male. The average age of the participants was 41.61 years, with a standard deviation of 8.56 years and an age range of 23-60 years. The average age of the patients who achieved total smoking cessation at 12 months was 43.6 years, with a standard deviation of 8.14 years and an age range of 33-60 years. The average age of the patients who achieved partial cessation at 12 months was 43 years, with a standard deviation of 7.07 years and an age range of $38-48$ years.

The smoking history data were as follows: average starting age of 16.48 years with a standard deviation of 2.94 years, and an age range of $13-25$ years; $82.61 \%$ of patients had made at least one previous attempt to stop smoking, and $17.39 \%$ had made five or more attempts; almost half, $47.83 \%$, had used no particular method to stop smoking in the past; and no patients had tried any pharmacological treatment other than NRT. In addition, $43.48 \%$ of patients identified three or more situations in which they found it difficult not to smoke.

The initial condition data revealed that $60.87 \%$ of patients smoked between eleven and 20 cigarettes per day; $26.09 \%$ of patients had a CO-oximetry level of between $7 \mathrm{ppm}$ and $10 \mathrm{ppm}$, $39.13 \%$ between $11 \mathrm{ppm}$ and $20 \mathrm{ppm}$, and 34.78\% of more than $20 \mathrm{ppm}$; and $43.48 \%$ presented low nicotine dependence, $30.43 \%$ moderate dependence, and $26.09 \%$ high dependence.

Figure 4 shows the smoking cessation results obtained at the 1, 3, 6, and 12 months follow-up visits. One month into the study, $73.91 \%$ of patients had achieved smoking cessation, and $26.09 \%$ abandoned the study. Of the patients who obtained a positive result, $76.47 \%$ achieved total smoking cessation ( $56.52 \%$ of the total number of patients) and $23.53 \%$ achieved partial smoking cessation $(17.39 \%$ of the total). None of the patients who completed the follow-up failed to comply with the treatment.

Three months into the study, $65.22 \%$ of patients achieved smoking cessation, $4.35 \%$ had not achieved it, and 30.43\% had abandoned the study. Of the patients who obtained a positive result, $66.67 \%$ achieved total smoking cessation (43.48\% of the total number of patients) and $33.33 \%$ achieved partial cessation $(21.74 \%$ of the total).



Figure 4 Smoking cessation results at the I-, 3-, 6-, and I2-month follow-up visits. 
Table I Smoking cessation results

\begin{tabular}{lllll}
\hline & Total cessation n (\%) & Partial cessation n (\%) & No cessation n (\%) & Abandoned n (\%) \\
\hline I month & $13(56.52 \%)$ & $4(17.39 \%)$ & $0(0 \%)$ & $6(26.09 \%)$ \\
3 months & $10(43.48 \%)$ & $5(21.74 \%)$ & $1(4.35 \%)$ & $7(30.43 \%)$ \\
6 months & $11(47.83 \%)$ & $3(13.04 \%)$ & $2(8.70 \%)$ & $7(30.43 \%)$ \\
I2 months & $10(43.48 \%)$ & $2(8.70 \%)$ & $3(13.04 \%)$ & $8(34.78 \%)$ \\
\hline
\end{tabular}

Six months into the study, $60.87 \%$ of patients achieved smoking cessation, $8.70 \%$ had not achieved it, and 30.43\% abandoned the study. Of the patients who obtained a positive result, $78.57 \%$ achieved total smoking cessation $(47.83 \%$ of the total number of patients) and $21.43 \%$ achieved partial cessation (13.04\% of the total).

Twelve months into the study, $52.18 \%$ of patients achieved smoking cessation, $13.04 \%$ had not achieved it, and $34.78 \%$ abandoned the study. Of the patients who obtained a positive result, $83.33 \%$ achieved total smoking cessation (43.48\% of the total number of patients) and $16.67 \%$ achieved partial cessation $(8.70 \%$ of the total; Table 1$)$. The rate of smoking cessation achieved by patients during the study period is shown in Figure 5.

\section{Discussion}

A very high percentage of the patients in our study accepted the offer of support from the pharmaceutical care service to help them stop smoking (92\%). In other studies, the number of patients declining the support of other pharmaceutical care services, such as medical follow-up, has been much higher. ${ }^{19}$ There are many intervention methods designed to improve patient health, ${ }^{20}$ but in our field, the most commonly used method is health campaigns. ${ }^{21}$ Promoting the service through an awareness campaign significantly increased the number of patients who enrolled in the pharmaceutical care program (from one patient to 22 patients).

The average rates of abstinence achieved after 6 and 12 months of treatment with NRT in other studies carried out in primary care and other health clinics are between $25 \%$ and $35 \% .^{16,22}$ In our study, the total abstinence rate was

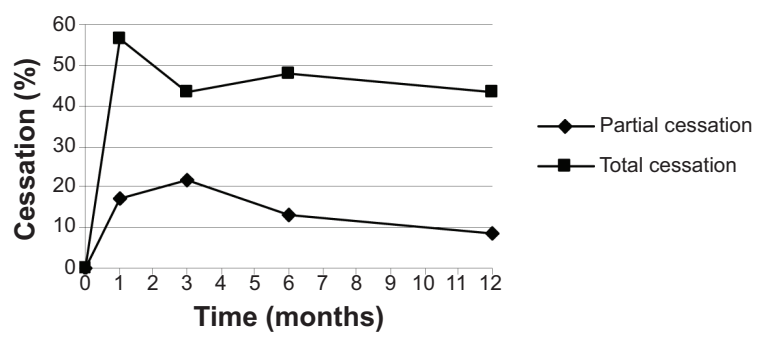

Figure $\mathbf{5}$ Rate of smoking cessation achieved by patients during the study period.
$47.83 \%$ at 6 months and $43.48 \%$ at 12 months, indicating that the inclusion of pharmacies in smoking cessation programs may improve health outcomes. Pharmaceutical care may be responsible for this result, thanks to the continuous, active intervention on the part of the pharmacist, achievable due to the pharmacist's proximity and access to the patient.

There were no significant differences in smoking cessation between the sexes, although the percentage of women participating in the study (69.57\%) was higher than that of men. As other authors have described, women are more likely to seek advice from pharmacies than men. ${ }^{23}$ The majority of studies carried out in primary care settings include similar numbers of men and women, ${ }^{17}$ and the rates of cessation are similar in both sexes in the published literature.

The possible limitations of this study are the number of study participants, and to avoid this limitation, an additional, multicenter study should be performed to include a number of different pharmacies in order to corroborate the results. In addition, the level of abstinence was obtained by measuring $\mathrm{CO}$ in exhaled air. Elevated $\mathrm{CO}$ values can only be detected by the CO-oximeter if the measurement is taken within 24 hours of tobacco consumption. Some patients may have tried to cover up a relapse by stopping smoking 48 hours prior to the test. This also represents a limitation of our study.

\section{Conclusion}

Advertising a smoking cessation program in a pharmacy increases the number of patients who use the pharmacy's smoking cessation service. Pharmaceutical care is an effective means of achieving smoking cessation, with total abstinence after 12 months observed in $43 \%$ of participating patients, representing an improvement over the results obtained in other health care settings. Given that smoking is a public health issue, pharmacy smoking cessation services should be systematically promoted at an institutional level in order to reduce the problems associated with smoking.

\section{Disclosure}

The authors report no conflicts of interest in this work. 


\section{References}

1. Banegas JR, Díez Gañan L, González Enríquez J, Villar Alvarez F, Rodríguez-Artalejo F. [Recent decrease in smoking attributable mortality in Spain]. Med Clin (Barc). 2005;124(20):769-771. Spanish.

2. International Union for Health Promotion and Education. The Evidence of Health Promotion Effectiveness: A Report for the European Commission by the International Union for Health Promotion and Education Shaping Public Health in a New Europe. Report by International Union for Health Promotion and Education for the European Commission. Part Two. Evidence Book. Madrid, Spain: 2000. Available from: http:// www.iuhpe.org/images/PUBLICATIONS/THEMATIC/EFFECTIVENESS/HPE_Evidence-2_EN.pdf. Accessed November 25, 2014.

3. Council for National Health Service. Formation in Health Promotion and Education. Report by the Working Group for the Promotion of Public Health of the Council for National Health Service. Madrid, Spain: Ministry of Health and Consumer Affairs; 2003.

4. Raw M, McNeill A, West R. Smoking cessation guidelines for health professionals. A guide to effective smoking cessation interventions for the health care system. Health education authority. Thorax. 1998;53 Suppl 5 Pt 1:S1-S19.

5. Sinclair HK, Bond CM, Stead LF. Community pharmacy personnel interventions for smoking cessation. Cochrane Database Syst Rev. 2004; 1:CD003698.

6. Forum of Pharmaceutical Care. Consensus document 2008. MSC, RANF, CGCOF, SEFAP, SEFAC, SEFH, FPCE, GIAFUG. Madrid, Spain: Forum of Pharmaceutical Care; 2008. Available from: http:// www.portalfarma.com/inicio/serviciosprofesionales/forodeattfarma/ Documents/FORO_At_farma.pdf. Accessed February 24, 2010.

7. Machuca M, Fernández-Llimos F, Faus MJ. Método Dáder. Dader method. Guide to pharmaceutical monitoring. GIAF-UGR. Granada. 2003.

8. Machuca M, Baena MI, Faus MJ. Guide to pharmaceutical indication. Pharmaceutical care investigation group. (CTS-131) University of Granada and Abbott Fundation 2005.

9. U.S. Department of Health and Human Services. Public Health Service. Clinical Practice Guideline: Treating Tobacco Use and Dependence. Washington, DC; 2000.

10. Jarvis MJ, Russell MA, Saloojee Y. Expired air carbon monoxide: a simple breath of tobacco smoke intake. Br Med J. 1980;281(6238): 484-485.

11. Clark KD, Wardrobe-Wong N, Elliott JJ, Gill PT, Tait NP, Snashall PD. Cigarette smoke inhalation and lung damage in smoking volunteers. Eur Respir J. 1998;12(2):395-399.
12. Zacny JP, Stitzer ML, Brown FJ, Yingling JE, Griffiths RR. Human cigarette smoking: effects of puff and inhalation parameters on smoke exposure. J Pharmacol Exp Ther. 1987;240(2):554-564.

13. Fagerstrom KO, Schneider NG. Measuring nicotine dependence: a review of the Fagerstrom Tolerance Questionnaire. J Behav Med. 1989;12(2):159-182.

14. Torrecilla García M, Dominguez Grandal F, Torres Lana A, et al. Recomendaciones en el abordaje diagnostico y terapeutico del fumador. Documento de consenso. Medifam. 2002;12:484-492. Spanish.

15. Pérez Trullen A, Clemente Jiménez ML, Morales Blánquez C. Terapias psicologicas en la deshabituacion tabaquica. Psiquis. 2001;22(6): 251-263. Spanish.

16. Camarelles Guillem F, Salvador Llivina T, Ramón Torell JM, et al. [Consensus on health assistance for smoking control in Spain]. Rev Esp Salud Publica. 2009;83(2):175-200. Spanish.

17. Stead LF, Perera R, Bullen C, Mant D, Lancaster T. Nicotine replacement therapy for smoking cessation. Cochrane Database Syst Rev. 2008;1:CD000146.

18. Aubin HJ, Karila L, Reynaud M. Pharmacotherapy for smoking cessation: present and future. Curr Pharm Des. 2011;17(14): 1343-1350.

19. Barris D, Faus MJ. An initiation for Dader methodology of pharmaceutical monitoring in a community pharmacy. Ars Pharm. 2003;44(3):225-237.

20. Díez E, Juárez O, Villamarín F. [Health promotion interventions based on theoretical models]. Med Clin (Barc). 2005;125(5):193-197. Spanish.

21. Dent LA, Harris KJ, Noonan CW. Tobacco interventions delivered by pharmacists: a summary and systematic review. Pharmacotherapy. 2007;27(7):1040-1051.

22. Silagy C, Lancaster T, Stead L, Mant D, Fowler G. Nicotine replacement therapy for smoking cessation. Cochrane Database Syst Rev. 2004;3:CD000146.

23. Baixauli VJ, Salar Ibáñez L, Barbero González A. Demanda de información en al Farmacia Comunitaria. Pharmaceutical Care España. 2004;6(3):136-144. Spanish. 


\section{Supplementary material}

Table SI Fagerstrom test for nicotine dependence

Points

I. How soon after you wake up do you smoke your first cigarette?

$\begin{array}{ll}\text { a) Within } 5 \text { minutes } & 3 \\ \text { b) } 6-30 \text { minutes } & 2 \\ \text { c) } 31-60 \text { minutes } & \text { I } \\ \text { d) After } 60 \text { minutes } & 0\end{array}$

2. Do you find it difficult to refrain from smoking in places where it is forbidden, eg, in church, at the library, in the cinema, etc?

a) Yes

b) No

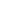

3. Which cigarette would you hate most to give up?

a) The first one in the morning

b) All others

4. How many cigarettes/day do you smoke?
a) 31 or more
b) $21-30$
c) $11-20$
d) 10 or less

5. Do you smoke more frequently during the first hours after waking up than during the rest of the day?
a) Yes
b) No

6. Do you smoke if you are so ill that you are in bed most of the day?

a) Yes

b) No

Total score

Low dependence ( 0 to 3 points)

Moderate dependence (4 to 6 points)

High dependence (7 to 10 points)

Note: Copyright @ 1989. Springer. Reproduced from Journal of Behavioral Medicine, 12, 1989, 159-182, Measuring nicotine dependence: a review of the Fagerstrom Tolerance Questionnaire, Fagerstrom KO, Schneider NG, Table 3, with kind permission from Springer Science and Business Media.'

\section{Reference}

1. Fagerstrom KO, Schneider NG. Measuring nicotine dependence: a review of the Fagerstrom Tolerance Questionnaire. J Behav Med. 1989; 12(2):159-182.

\section{Publish your work in this journal}

Patient Preference and Adherence is an international, peer-reviewed, open access journal that focuses on the growing importance of patient preference and adherence throughout the therapeutic continuum. Patient satisfaction, acceptability, quality of life, compliance, persistence and their role in developing new therapeutic modalities and compounds to optimize

\section{Dovepress}

clinical outcomes for existing disease states are major areas of interest for the journal. This journal has been accepted for indexing on PubMed Central. The manuscript management system is completely online and includes a very quick and fair peer-review system, which is all easy to use. Visit http://www. dovepress.com/testimonials.php to read real quotes from published authors.

\footnotetext{
Submit your manuscript here: http://www.dovepress.com/patient-preference-and-adherence-journal
} 